\title{
A clinicoepidemiological study of facial hypermelanosis among females of reproductive age group
}

\author{
Sameer Abrol', Rohini Sharma²
}

\begin{abstract}
${ }^{I}$ M.D. Medicine. GMC Jammu, Jammu and Kashmir, India, ${ }^{2}$ Assistant professor, Department of Dermatology, GMC Rajouri, Jammu and Kashmir, India
\end{abstract}

Corresponding author: Dr. Rohini Sharma, E-mail: dr.rohini_sharma@yahoo.co.in

\begin{abstract}
Background: Facial hypermelanosis has great psychological and aesthetic complications attached to it specially in females. A number of factors like genetic, environmental, systemic, work in consortium to give rise to various types of hypermelanosis. Women in the 15-49 years age group, which is the reproductive age group are influenced by various hormonal alterations along with external and systemic agents thus manifesting as various types of hypermelanosis. Aims and objectives: This study was undertaken to assess the clinical and epidemiological aspects of various types of facial hypermelanosis and various factors implicated. Material and methods: A total of 350 women in the age group of 15- 49 years were taken up for the study. A detailed clinical history, thorough examination was done in all patients. Relevant investigations were carried out. All the results were statistically analyzed and inferences were drawn. Results: A total of 350 women were taken up for study. Maximum patients $(133,38 \%)$ were in the age group of $26-35$ years. Among various hypermelanosis, maximum women $(128,36.5 \%)$ came with the complaint of melasma, $90(25.7 \%)$ women with post inflammatory hypermelanosis, 50(14.3\%)females with periorbital hypermelanosis. In our study, melasma, post inflammatory hyperpigmentation due to acne, acanthosis nigricans formed a major share in the 15-49 years age group thus suggesting the role of hormonal alterations and rising PCOS. Conclusion: Females are under considerable psychological and societal pressure. Besides adequate treatment, the role of hormonal alterations, life style factors, occupation in the above said age group needs to be ascertained by more such studies.
\end{abstract}

Key words: Facial hypermelanosis; Reproductive age group; Hormonal alterations

\section{INTRODUCTION}

Hypermelanosis affecting the face is a commonly encountered problem among Indian patients seeking dermatological advice. Facial hypermelanosis carries immense psychological impact owing to its evident cosmetic disfigurement and social stigmas attached to it [1]. Moreover, people of Asian and African descent constitutively have a darker phenotype which is more vulnerable to pigmentation [2]. Facial hypermelanosis encompasses a myriad of clinical entities which are commonly encountered: melasma, peri-orbital melanosis, postinflammatory hyperpigmentation, lichen planus pigmentosus, Riehl's melanosis, freckles and lentigenes, exogenous ochronosis, acanthosis nigricans, erythema dyschromicum perstans, and uncommonly poikiloderma of Civatte, erythromelanosis follicularis of face and neck, nevus of Ota, some to be named. Most of the studies worldwide on facial hypermelanosis have reported a female predominance [3,4]. In India, a great heterogeneity was reported among women in the facial skin color with hypermelanosis accounting for a major share [5]. Besides constitutive pigmentation, a complex interplay of genetic, environmental, systemic diseases, hormonal factors along with use of external agents, have been reported in the causation of various types of facial hypermelanosis [6]. Women in the reproductive age group ( $15-49$ years) undergo hormonal alterations

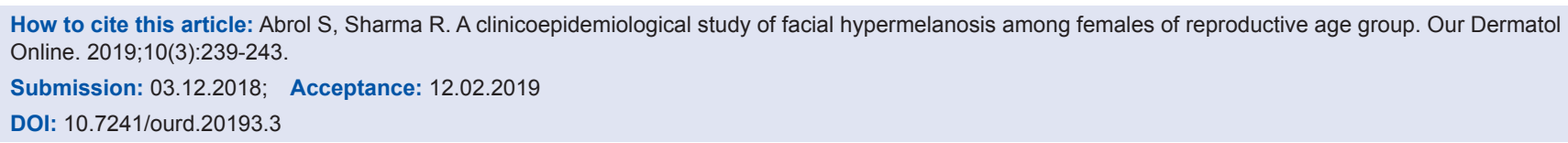


right from menarche to menopause thus somewhere making them more prone to hypermelanosis, specially melasma [7]. Also, excessive exposure to sunshine on account of occupation or agricultural work, use of beautifying creams, cosmetics, use of drugs also increase the chances of facial hypermelanosis in the same age group. This study was undertaken to assess the clinical and epidemiological aspects of facial hypermelanosis in women in the 15-49 years age group.

\section{MATERIAL AND METHODS}

This was a prospective study carried out over a period of 3 months. A total of 350 women in the age group of 15- 50 years who presented to the outpatient department at our dermatology department with facial hypermelanosis were taken up for the study after obtaining written informed consent. These were divided into various age groups: $15-25$ years, $26-35$ years, $36-45$ years, $>45$ years. A detailed clinical history regarding age of onset, duration, any aggravating factors, family history was taken. History about various causative factors implicated: sun exposure, occupation, use of cosmetics or chemical agents, drug intake or presence of any systemic illnesses was also noted. Any history of diabetes, thyroid disorders or any hormonal abnormalities was asked too. A detailed general physical examination regarding distribution of pigmentation, whether dermal or epidermal was noted. Also evidence of any other systemic diseases or hormonal abnormalities was also examined. Woods lamp examination was done in all patients and biopsy was taken wherever necessary. Laboratory investigations were done wherever necessary and included complete haemogram, blood glucose levels, serum insulin, renal and liver function tests, thyroid profile and relevant hormonal abnormalities. All the results were statistically analyzed and inferences were drawn.

\section{RESULTS}

A total of 350 women were taken up for study. Maximum patients $(133,38 \%)$ were in the age group of $26-35$ years followed by $105(30 \%)$ patients in the $36-45$ years age group. In the $15-25$ years age group, there were $65(18.7 \%)$ patients and 47 women were in the $45-49(13.4 \%)$ years age group. Among various hypermelanosis, maximum women $(128,36.5 \%)$ came with the complaint of melasma (Fig. 1), followed by 90 (25.7\%) women with post inflammatory hypermelanosis, $50(14.3 \%)$ females with periorbital hypermelanosis. The distribution of various types of hypermelanosis is given in Table 1. The age group wise distribution of various hypermelanosis is shown in Table 2.

Females with melasma formed a major share. Most of these were in the age group of $26-45$ years. The most common pattern seen was malar seen in 55 (43\%) females followed by centrofacial $(41,32 \%)$ and mandibular patterns $(32,25 \%)$. Woods lamp examination was done in all patients of melasma. Epidermal pigmentation was seen in 44 (34.3\%) patients, dermal in 38 (29.6\%) females, mixed in 31 $(24.2 \%)$ females and indeterminate pigmentation in $15(11.7 \%)$ patients. Among various predisposing factors, pregnancy was the major predisposing factor seen in $75(58.5 \%)$, use of oral contraceptive pills(OCP's) and other hormonal supplements in 23 $(17.9 \%)$ females. Few females were taking OCP's and hormonal supplements were suffering from PCOS. In $16(12.5 \%)$ females, thyroid dysfunction was seen. 38 $(29.6 \%)$ out of 128 females gave sun exposure as the

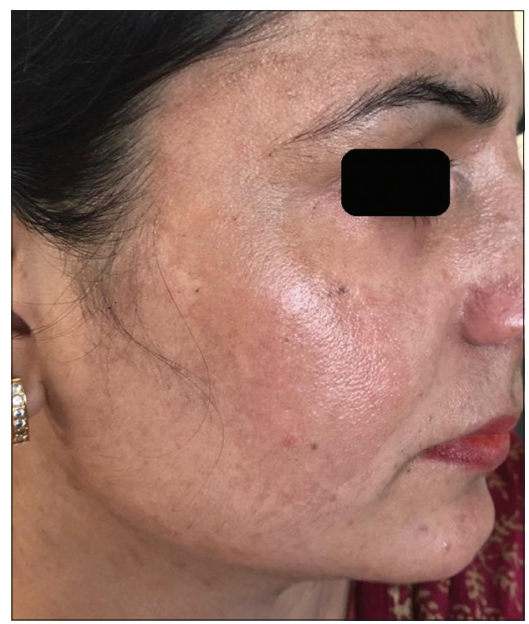

Figure 1: A female with epidermal melasma.

Table 1: Showing distribution of various melanosis

\begin{tabular}{lc}
\hline Facial hypermelanosis & Number of patients(\%) \\
\hline Melasma & 128 \\
Post inflammatory hyperpigmentation & $90(25.7)$ \\
Peri orbital melanosis & $50(14.3)$ \\
Freckles/lentigines & $31(8.8)$ \\
Lichen planus pigmentosus & $14(4)$ \\
Acanthosis nigricans & $12(3.4)$ \\
Riehl's melanosis & $7(2)$ \\
Pigmented cosmetic dermatitis & $5(1.4)$ \\
Ochronosis & $5(1.4)$ \\
Naevus of ota & $2(.5)$ \\
Miscellaneous & $6(1.7)$ \\
Drug induced pigmentation & 2 \\
Porphyrias & 1 \\
Systemic diseases & 3 \\
\hline
\end{tabular}


Table 2: Showing distribution of various hypermelanosis among various age groups

\begin{tabular}{|c|c|c|c|c|c|}
\hline Types of melanosis & $15-25$ years & 26-35 years & $36-45$ years & $46-49$ years & Total \\
\hline Melasma & 10 & 76 & 34 & 8 & 128 \\
\hline Post inflammatory hyperpigmentation & 9 & 24 & 33 & 24 & 90 \\
\hline Peri orbital melanosis & 21 & 13 & 10 & 6 & 50 \\
\hline Freckles/lentigens & 14 & 9 & 6 & 2 & 31 \\
\hline Lichen planus pigmentosus & 3 & 4 & 6 & 1 & 14 \\
\hline Acanthosis nigricans & 2 & 3 & 5 & 2 & 12 \\
\hline Riehl's melanosis & 2 & 0 & 3 & 2 & 7 \\
\hline Pigmented cosmetic dermatitis & 0 & 1 & 3 & 1 & 5 \\
\hline Ochronosis & 0 & 1 & 3 & 1 & 5 \\
\hline Naevus of ota & 2 & 0 & 0 & 0 & 2 \\
\hline Miscellaneous & & & & 0 & 6 \\
\hline Drug induced & 2 & 0 & 0 & 0 & \\
\hline Porphyrias & 0 & 2 & 0 & 0 & \\
\hline Systemic & 0 & 0 & 2 & 0 & \\
\hline Total & 65 & 133 & 105 & 47 & 350 \\
\hline
\end{tabular}

aggravating factor owing to prolonged exposures to sun during working in fields among rural women or travelling as part of their occupation among others in addition to above causes. The second most common type of hypermelanosis among females was post inflammatory hyperpigmentation (PIH). Maximum cases of hyperpigmentation was attributed to severe acne seen in 56 (62.2\%) females and out of these, 39 females had evidence of hormonal imbalance in the form of Poly Cystic Ovarian Syndrome. Females with peri orbital melanosis mostly belonged to $<30$ years age group and major predisposing factors were genetic predisposition (21 females), stress and inadequate sleep (9), excessive exposure to laptop or mobile sunscreens (8). Peri-orbital oedema and skin laxity also was seen in 6 females. In the rest evidence of atopy and air borne contact dermatitis was seen. Freckles and lentigines (Fig. 2) were seen in 31 females and genetic factors along with sun exposure were implicated. Lichen planus pigmentosus were seen in 14 (4.4\%) patients. Sun exposure was the most common aggravating factor. 5 patients reported the use of mustard oil and amla oil which led to the development of lichen planus pigmentosus. The pigmentation ranged from slate gray to brownish black. The forehead and the temples were most commonly involved. Most women belonged to 35-49 years of age group. Among 12 patients of acanthosis nigricans, diabetes was present in 3. In 7 patients, obesity was present leading to altered insulin levels. There were 2 patients of proven PCOS on treatment who had acanthosis nigricans. Other hypermelanosis seen less commonly were: Riehl'smelanosis, pigmented cosmetic dermatitis, ochronosis due to abuse of hydroquinone and naevus of ota. Also drug induced hyperpigmentation due to clofazimine and minocycline was also seen.

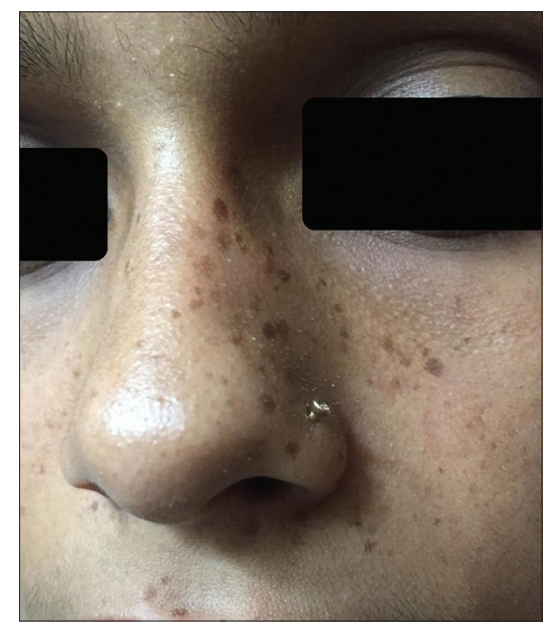

Figure 2: A young female with lentigines

\section{DISCUSSION}

Number of females with facial hyper melanosis is seeing an upwards trend among the out patients presenting to dermatologists and various contributing factors are: increased awareness, society and marriage pressures to look more beautiful, use of drugs and cosmetics, increased sun exposure and rising obesity and other hormonal abnormalities due to changing life styles. In our study involving females in the reproductive age group which witnesses multiple hormonal alterations, the most common hypermelanosis seen was melasma present in $36.5 \%$ of the patients. Multiple studies across India also have found melasma to be the most common hypermelanosis and maximum women belong to the same age group as in our study [5,8]. In our study malar pattern was the most common in $43 \%$ followed by centrofacial seen in 32\% and mandibular pattern seen in $25 \%$ similar to other studies [8,9]. On the contrary various studies have reported centrofacial 
pattern to be the most common $[10,11]$. The most common precipitating factor was pregnancy $(58.2 \%)$ in our study followed by OCP's and hormonal supplements (17.9\%) thus giving impetus to the role of hormones in its genesis which has been reported in other studies as well [12-14]. Exposure to ultraviolet rays have been found to be crucial in various studies as it leads to increased levels of various hormones: alphamelanocyte-stimulating hormone, corticotrophin and also interleukin (IL)-l that, in turn, results in increased melanin production [15]. In our study also sunlight was implicated in the exacerbation of melasma in $29.6 \%$ in concordance with other studies which also reported sunlight as the exacerbating factor [16-18]. Epidermal pattern was the most common in our study similar to another study [19]. In our study, the second most common facial hypermelanosis was postinflammatory hyperpigmentation seen in $25.7 \%$ of the females. In $\mathrm{PIH}$, skin inflammation results in the production of cytokines, prostaglandins, leukotrienes which further stimulate melanin synthesis. The most common cause attributed was acne. Multiple other studies have also reported similar findings $[5,20]$. In our study many females with acne were diagnosed cases of PCOS thus implicating hormonal role. In our study we found a lower incidence of periorbital melanosis at $14.3 \%$ as compared to other studies which had higher prevalence [20]. Another study reported an even lower prevalence [8]. This could be due to genetic or regional variation. In our study, major factor was genetic predisposition, inadequate sleep, exposure to laptops and mobiles, atopy and airborne contact dermatitis. These were well in concordance with various other studies $[8,21,22]$. Freckles and lentigenes was also seen in our study with a prevalence of $8.8 \%$. Freckles are mostly seen in fairer skin with sun exposure also implicated. Lentigines can occur anywhere in body and have a genetic role majorly. Lichen planus pigmentosus is a variant of lichen planus and prevalence in our study was similar to other studies and most of the patients were $>35$ years well in accordance to other studies $[8,23,24]$. Acanthosis nigricans comprises of hyperpigmented velvety plaques mostly over the flexures but involves the face as well. In our study obesity and diabetes were the major reasons but PCOS was also seen. Various other studies have reported similar findings [25]. In our study, PCOS resulting in hormonal imbalances and its treatment was implicated in melasma, PIH resulting from acne, acanthosis nigricans thus suggesting rising trend of it in the above studied age group. Also in our study, melasma, post inflammatory hyperpigmentation due to acne, acanthosis nigricans formed a major share in the 15-49 years age group thus suggesting the role of hormonal alterations and rising PCOS. Riehl's melanosis, pigmented cosmetic dermatitis, ochronosis due to abuse of hydroquinone and naevus of Ota, facial pigmentation due to clofazimine in a leprosy patient and minocycline in another patient were other less common hypermelanosis observed.

\section{CONCLUSION}

Facial hypermelanosis is commonly encountered by dermatologists and has multiple patterns. The female gender is particularly vulnerable to the social and psychological constraints of it. The role of hormonal alterations, life style factors, occupation in the above said age group needs to be ascertained by many more such studies.

\section{Statement of Human and Animal Rights}

All procedures followed were in accordance with the ethical standards of the responsible committee on human experimentation (institutional and national) and with the Helsinki Declaration of 1975, as revised in 2008 .

\section{Statement of Informed Consent}

Informed consent was obtained from all patients for being included in the study.

\section{REFERENCES}

1. Bhatia V, Bubna AK, Subramanyam S, Veeraraghavan M, Rangarajan S, Sankarasubramanian A. Stubborn facial hypermelanosis in females: A clinicopathologic evaluation. Pigment Int [serial online]. 2016;3:83-9.

2. Cheng J, Vashi NA. Treatment strategies for hyperpigmentation. Dermatoanthropol Ethnic Skin Hair. 2017;4:417-36.

3. Pichardo R, Vallejos Q, Feldman SR, Schulz MR, Verma A, Quandt SA, et al. The prevalence of melasma and its association with quality of life among male migrant Latino workers. Int J Dermatol. 2009;48:22-6.

4. Pawaskar MD, Parikh P, Markowski T, McMichael AJ, Feldman SR, Balkrishnan R. Melasma and its impact on health-related quality of life in Hispanic women. J Dermatolog Treat. 2007;18:5-9.

5. Hourblin V, Nouveau S, Roy N, de Lacharrière O. Skin complexion and pigmentary disorders in facial skin of 1204 women in 4 Indian cities. Indian J Dermatol Venereol Leprol. 2014; 80: 395-401.

6. Shahana M, Padma A, Khan PM. Study of clinical patterns of facial pigmentation. Int J Biomed Res. 2016;7:94-8.

7. Grimes PE, Yamada N, Bhawan J. Light microscopic, immunohistochemical and ultrastructural alteration in patients with melasma. Am J Dermatopathol. 2005;27:96-101.

8. Hassan I, Aleem S, Bhat Y S, Anwar P. A clinico-epidemiological study of facial melanosis. Pigment Int. 2015;2:34-40. 
9. Goh CL, Dlova CN. A retrospective study on the clinical presentation and treatment outcome of melasma in a tertiary dermatological referral centre in Singapore. Singapore Med J. 1999; 40:455-8.

10. Achar A, Rathi SK. Melasma: a clinico-epidemiological study of 312 cases. Indian J Dermatol. 2011;56:380-382.

11. Guinot C, Cheffai S, Latreille J, Dhaoui MA, Youssef S, Jaber K, et al. Aggravating factors for melasma: a prospective study in 197 Tunisian patients. J Eur Acad Dermatol Venereol. 2010;24:1060-9.

12. Puri N, Puri N. A study on dermatoses of pregnancy. Our Dermatol Online. 2013;4:56-60.

13. Moin A, Jabery Z, Fallah N. Prevalence and awareness of melasma during pregnancy. Int J Dermatol. 2006;45:285-8.

14. Martin AG, Leal-Khouri S. Physiologic skin changes associated with pregnancy. Int J Dermatol. 1992;31:375-378.

15. Kang HY, Hwang JS, Lee JY, Ahn JH, Kim JY, Lee ES, et al. The dermal stem cell factor and c-kit are overexpressed in melasma. $\mathrm{Br}$ J Dermatol 2006;154:1094-9.

16. Lee AY. Recent progress in melasma pathogenesis. Pigment Cell Melanoma Res. 2015;28:648-60.

17. Suggs AK, Hamill SS, Friedman PM. Melasma: update on management. Semin Cutan Med Surg. 2018;37:217-25.

18. Jung YS, Bae JM, Kim BJ, Kang JS, Cho SB. Periorbital melasma: Hierarchical cluster analysis of clinical features in Asian patients. Skin Res Technol. 2017;23:552-7.

19. Nicolaidou E, Antoniou C, Katsambas AD. Origin, clinical presentation and diagnoses of facial hypermelanoses. Dermatol Clin. 2007;25:321-6.

20. Nouveau S, Divya A, Kohli M, Bernerd F, Misra N, Nayak CS. Skin hyperpigmentation in Indian population: Insights and best practice. Indian J Dermatol. 2016;61:487-95.

21. Ranu H, Thng S, Goh BK, Burger A, Goh CL. Periorbital hyperpigmentation in Asians: An epidemiologic study and a proposed classification. Dermatol Surg. 2011;37:1297-303.

22. Sheth PB, Shah HA, Dave JN. Periorbital hyperpigmentation: A study of its prevalence, common causative factors and its association with personal habits and other disorders. Indian J Dermatol 2014; 59:151-7.

23. Amatya B. Ashy dermatosis: A comprehensive review. Our Dermatol Online. 2017;8:143-8.

24. Nag F, Ghosh A, Chatterjee G, Choudhary N. Lichen planus pigmentosus: two atypical presentation. Our Dermatol Online. 2013; 4:78-9.

25. Puri N. A study of pathogenesis of acanthosis nigricans and its clinical implications. Indian J Dermatol. 2011;56:678-83.

Copyright by Sameer Abrol, et al. This is an open-access article distributed under the terms of the Creative Commons Attribution License, which permits unrestricted use, distribution, and reproduction in any medium, provided the original author and source are credited.

Source of Support: Nil, Conflict of Interest: None declared. 